This is a post-acceptance, pre-publication version of the manuscript:

Scherman, R., Misca, G., Rotabi, K. \& Selman, P. (2016). Global commercial surrogacy and international adoption: A brief comparison of similarities and differences. Adoption \& Fostering. 4O(1) 30-45. doi: 10.1177/0308575915626376

\title{
GLOBAL COMMERCIAL SURROGACY AND INTERNATIONAL ADOPTION: PARALLELS AND DIFFERENCES
}

\begin{abstract}
Over the decades, there have been numerous trends in the formation of family for those experiencing infertility. Adoption-initially domestic but now mostly international-has long been a prevailing method, with a dual outcome of also finding homes for parentlesschildren. Those would-be parents with a stronger desire for genetic-relatedness have turned to the assisted reproductive technologies for the creation of their families. Here in the $21^{\text {st }}$ century, capitalising on globalisation and advances in medical sciences and communication, global commercial surrogacy is emerging as a dominant method of family formation. In publishing this paper in the Adoption $\mathcal{E}^{2}$ Fostering journal, our primary objective was to provide its readership with an introductory look at global surrogacy, thereby expanding an awareness of surrogacy in an audience whose work has traditionally been in the care and protection of children through foster care and adoption. A secondary aim was to see where the longstanding field of adoption could potentially inform the burgeoning field of global commercial surrogacy. To achieve these aims, we use international adoption and the adoption-triangle as a framework, as we look at the similarities and differences between the adoptive and commissioning parents; the birth mother and the surrogate mother; and the adopted children and the children born of global surrogacy.
\end{abstract}

\section{$\underline{\text { Keywords }}$}

International adoption, Intercountry adoption, Global surrogacy, Commercial surrogacy 
This is a post-acceptance, pre-publication version of the manuscript:

Scherman, R., Misca, G., Rotabi, K. \& Selman, P. (2016). Global commercial surrogacy and international adoption: A brief comparison of similarities and differences. Adoption \& Fostering. 4O(1) 30-45. doi: 10.1177/0308575915626376

\section{Introduction}

In August of 2014, a flood of media interest arose about the child born of a global commercial surrogacy arrangement, who was then ostensibly abandoned by the contracting parents (Rogers \& Watcharasakwet, 2014; Topping \& Foster, 2014). The "Baby Gammy" story was particularly alarming because the child (a boy with a twin sister who went home with the commissioning parents) was apparently left behind due to being born with Down Syndrome. The media storm lasted weeks, resulting in more than 2000 media and Internet stories. Looking deeper, one sees that this story was merely the latest in a growing series of media reports on commercial surrogacy.

The public was finally gaining some awareness of the complex issues surrounding global commercial surrogacy. However, for many of those working in the field, the Baby Gammy story was just one more example of the grave need for international regulations on the practice. Interestingly, the story went viral within days of the International Forum on Intercountry Adoption \& Global Surrogacy, an event held in The Hague, The Netherlands in August of 2014 to which approximately 80 delegates were invited-scholars, activists and professionals from around the world involved with international adoption and/or global surrogacy ${ }^{1}$. One of the key aims of that event was to critically consider the possible need for international regulations for global surrogacy. For a fuller consideration of this issue ${ }^{2}$, which is beyond the scope of the current paper, please see Cheney (A\&F, same issue). Another primary objective of the Forum was to consider the parallels between commercial crossborder surrogacy and intercountry adoptions. It was from those discussions that this paper evolved. In it, the authors (all of whom attended the forum) provide the Adoption \& Fostering readership a primer of sorts on global commercial surrogacy, as considered through the lens of international adoption and the adoption-triangle - a framework believed to be wellunderstood by the readership. In this context, the paper draws together points of similarity and difference between: (1) the adoptive parents and commissioning parents; (2) the relinquishing birth mother and the surrogate; and (3) the adopted children and the children born of global surrogacy. At the end of the paper, we will summarise the lessons that the discipline of adoption can offer the field global commercial surrogacy. 
This is a post-acceptance, pre-publication version of the manuscript:

Scherman, R., Misca, G., Rotabi, K. \& Selman, P. (2016). Global commercial surrogacy and international adoption: A brief comparison of similarities and differences. Adoption \& Fostering. 4O(1) 30-45. doi: 10.1177/0308575915626376

\section{The decline of international adoptions and the rise in global surrogacies}

Since 2004 the annual number of intercountry adoptions (ICA) recorded by 23 receiving states, including all the main destination countries in this movement of children, has fallen from over 45,000 in 2004 to around 16,000 in 2013 (See Table 1). One consequence of this decline $^{3}$ is that there are many prospective adoptive parents who have been approved, who have been waiting for many years to receive a child (San Roman \& Marre, 2014), but who are now being told that they may never have a placement unless they are prepared to take an older child, a sibling group or a child with 'special needs' (International Social Service, 2014). It has also been reported that 1 in 10 (first-world) couples are experiencing difficulties conceiving a child naturally (Twine, 2011). The global rise in infertility coupled with the declining rates and changing nature of ICA, means that people will naturally seek out alternative solutions to satisfy their desires to become parents. Many are now turning to various forms of assisted reproductive technologies (ART), with a sharp rise in global commercial surrogacy (GCS) since 2005/6 (Rotabi \& Bromfield, 2012; Twine, 2011). GCS may also be quicker (and cheaper) than ICA, with the added advantage of potentially getting an infant with some genetic link.

Table 1:

Intercountry adoptions to 23 receiving countries, 2004 to 2013 (top 5 ranked by number of children received in 2004)

\begin{tabular}{|l|l|l|l|l|l|l|}
\hline Country & $\mathbf{2 0 0 4}$ & $\mathbf{2 0 0 6}$ & $\mathbf{2 0 0 8}$ & $\mathbf{2 0 1 0}$ & $\mathbf{2 0 1 2}$ & $\mathbf{2 0 1 3}$ \\
\hline USA & $\mathbf{2 2 , 8 8 4}$ & 20,679 & 17,438 & 12,149 & 8,668 & 7,094 \\
Spain & $\mathbf{5 , 5 4 1}$ & 4,472 & 3,156 & 2,891 & 1,669 & 1,191 \\
France & $\mathbf{4 , 0 7 9}$ & 3,977 & 3,271 & 3,504 & 1,569 & 1,343 \\
Italy & 3,402 & 3,188 & 3,977 & $\mathbf{4 , 1 3 0}$ & 3,106 & 2,825 \\
Canada & $\mathbf{1 , 9 4 9}$ & 1,568 & 1,614 & 1,660 & 1,162 & 1,243 \\
\hline Total to 23 & & & & & & \\
states a & $\mathbf{4 5 , 2 8 1}$ & $\mathbf{3 9 , 4 9 2}$ & $\mathbf{3 4 , 4 7 9}$ & $\mathbf{2 8 , 8 0 8}$ & $\mathbf{1 9 , 3 4 1}$ & $\mathbf{1 6 , 1 6 7}$ \\
\hline \% to USA & $51 \%$ & $52 \%$ & $50 \%$ & $42 \%$ & $45 \%$ & $44 \%$ \\
\hline
\end{tabular}

a Statistics for all 23 states can be found at Selman (2015).

In India, CGS was legalised in 2002 (DasGupta \& DasGupta, 2010), and subsequently became the main source for surrogates worldwide. More recently there has been a growth of surrogacy in other countries including Thailand, Mexico and Ukraine. The banning of GCS 
This is a post-acceptance, pre-publication version of the manuscript:

Scherman, R., Misca, G., Rotabi, K. \& Selman, P. (2016). Global commercial surrogacy and international adoption: A brief comparison of similarities and differences. Adoption \& Fostering. 4O(1) 30-45. doi: 10.1177/0308575915626376

in Thailand after the Baby Gammy scandal (Wang 2015) means the market will likely shift to new sites, with the most attractive being those where there is already a medical tourism model as is the case with Mexico. GCS remains legal in India but new legislation was proposed in 2014 (Indian News, 2014) that will regulate more aspects of the practice.

There are no accurate figures on the number of births from GCS arrangements, but in 2013 the International Reference Centre for the Rights of Children Deprived of their Family, an organisation set up within the Institute of Social Sciences, estimated that approximately 20,000 children were born annually through the process-more than the number of international adoptions in 2012, and that the numbers were expected to increase. Cuthbert and Fronek (2014) reported that since the first known 'off-shore' commercial surrogacy in Australia in 2009, the number has risen rapidly so that by 2013 GCS outnumbered ICA in that country.

Likewise, in the UK, the number of GCS has been rising with India and the USA the favoured destinations in 2010-11 (Crawshaw, Blyth, \& van den Akker, 2013). The Indian Council of Medical Research has reported around 3,000 clinics (Darnovsky \& Beeson 2014). In the USA, since 2010, the consulting service, World of Surrogacy, has helped more than 600 couples build their families through GCS and the California-based medical tourism agency, Planet Hospital, claims to have arranged even more in India and Mexico between 2006 and 2014. In March 2012, the Permanent Bureau of the Hague Conference on Private International Law cited research estimating a nearly $1000 \%$ increase in GCS in the four years between 2006 and 2010 (Hague Conference on Private International Law, 2012).

In the USA, where commercial surrogacy is legal in many states, costs range from $\$ 50,000$ to $\$ 120,000$, compared to $\$ 10,00$ to $\$ 20,000$ in India. In $2008 / 9$, the Indian commercial surrogacy 'industry' was estimated to bring in 450-500 million US dollars a year (DasGupta \& DasGupta, 2010) and by 2012 surrogacy 'tourism' was estimated by the Confederation of Indian Industry to be worth $\$ 2.3$ billion.

\section{The legal standing of commercial versus altruistic surrogacy}

One reason for the rapid increase in GCS is the fact that commercial surrogacy is illegal in many countries, including Australia, Canada, France, Italy, New Zealand, the UK, and in parts of the USA. One of the main reasons for this is the exchange of money. Commercial surrogacy involves the commissioning parents paying the surrogate a sum of money that exceeds the costs of her medical expenses. By contrast, altruistic surrogacy, which is voluntary and unpaid, 
This is a post-acceptance, pre-publication version of the manuscript:

Scherman, R., Misca, G., Rotabi, K. \& Selman, P. (2016). Global commercial surrogacy and international adoption: A brief comparison of similarities and differences. Adoption \& Fostering. 4O(1) 30-45. doi: 10.1177/0308575915626376

is often perceived as more acceptable (Anleu, 1992). As such, this type of surrogacy arrangement is legal in many countries, although usually still subject to regulations designed to protect all parties, including the surrogate and especially the offspring. ${ }^{4}$ Nonetheless, some of these regulations are considered too restrictive, resulting in the citizens of those countries seeking GCS arrangements in other countries. Another reason for the growth of GCS is the strict criteria of some 'source countries' involved in ICA, many of which will not place children with (e.g.) older or same-sex couples (Sifris, 2014).

\section{A focus on gestational surrogacy}

In traditional surrogacy, pregnancy may result from coitus, but more often it is brought about from artificial insemination (AI; the transfer of embryos into a woman's uterus). The surrogate may use her own eggs mixed with the sperm of either the contracting male or donated sperm. In such cases, the surrogate will be the genetic parent of any resulting offspring. On the other hand, an embryo (belonging to either the contracting couple or donated) may be transferred into the surrogate. When this occurs, the surrogate is referred to as a gestational carrier, who will be genetically unrelated to the offspring. This is the most common scenario in GCS, and the only legal GCS arrangement allowable in India (as the rules there require that the embryo be genetically related to one or both of the commissioning parents). Throughout the remainder of the paper, it is gestational surrogacy that we will be discussing.

In the next three sections, we offer a description of surrogacy by way of comparisons between the commissioning parents, the surrogate mother and the offspring of commercial surrogacy, and their ICA counterparts. 
This is a post-acceptance, pre-publication version of the manuscript:

Scherman, R., Misca, G., Rotabi, K. \& Selman, P. (2016). Global commercial surrogacy and international adoption: A brief comparison of similarities and differences. Adoption \& Fostering. 4O(1) 30-45. doi: 10.1177/0308575915626376

\section{Commissioning parents as compared with intercountry adoptive parents}

Referred to interchangeably as intended, commissioning or contracting parents, due to the fact they will commission or contract with a surrogate for a baby, these would-be parents are described below, as contrasted with ICA parents.

\section{Motives for choosing GCS and ICA}

The desire to be parents - and preferably genetically related to their offspring - is the fundamental motivation for people to consider surrogacy. In this context, commissioning parents appear to have much in common with ICA parents who may be struggling with infertility (Zheng \& Lee, 2011). Alternatively, while many ICA parents engage in adoption as a method of bringing children into otherwise childless homes, ICA can also be about finding homes for parentless children. In this later context, it is not infertility that is the driving force but instead, humanitarianism or an act of religious faith to rescue (Joyce, 2013) that sends families overseas in search of children. Even if infertility is the catalyst, it runs in fortunate tandem with the historically constructed 'public good' of providing homes for children (Fronek \& Cuthbert, 2012).

\section{Characteristics of parents in GCS and ICA}

The quest to have a child is undoubtedly facilitated by the resources that prospective parents in both GCS and ICA are able to draw upon. Research tells us that the socioeconomic status (SES) of commissioning couples, for example, is significantly higher than the general population (Ciccarelli \& Beckman, 2005), which may not be surprising given the costs involved in GCS. Research also shows that commissioning mothers tend to be older and most are university-educated (van der Akker, 2007). Similarly, adoptive couples are selected on their ability to invest time and money into the adoption process; thus typically, adoptive parents also have higher levels of income, education and are older than the general population (Fisher, 2003).

Retrospective studies also tell us that ICA adoptive parents are highly committed, providing adaptive parenting to the often-special needs children and demonstrating great resilience as illustrated in low breakdown rates (Misca, 2013). Similarly, GCS parents have good psychological well-being (van den Akker, 2007; Golombok et al., 2006a), and good adaption to parenthood, as well as warmth and attachment-related behaviours towards their infants (Golombok, Murray, Jadva, MacCallum, \& Lycett, 2004; Golombok et al., 2006a). In terms of family demographics, many ICA adoptive parents have other children, by natural birth, fostering or through other adoptions (Misca, 2013, 2014). By contrast, fewer GCS parents 
This is a post-acceptance, pre-publication version of the manuscript:

Scherman, R., Misca, G., Rotabi, K. \& Selman, P. (2016). Global commercial surrogacy and international adoption: A brief comparison of similarities and differences. Adoption \& Fostering. 4O(1) 30-45. doi: 10.1177/0308575915626376

appear to have pre-existing children in their families (Golombok et al., 2004, 2006b). Nonetheless, contemporary media is increasingly providing examples of celebrities that are commissioning surrogates to help add to their existing families of both birth and adopted children. Nicole Kidman and Keith Urban, for instance, provide such a high-profile hybrid family, having a naturally conceived child, two adopted children and a surrogate child (Hornery, 2011).

\section{Selection processes in GCS and ICA}

Among the contested aspects of both GCS and ICA is the idea of selection and approval process. In this comparison we see a fundamental difference between GCS and ICA. In ICA, parents are selected to meet the needs of a specific child. By way of often intrusive and timeconsuming assessments, prospective parents are vetted and carefully considered by social workers who make observations (and judgments) on the prospective parents, generally and for the placement of a specific child (Crea, 2012). This investigative process is considered paramount to protect the interests of the children (Widdows \& MacCallum, 2002). Thus, it is the children's needs that drive the processes and determine the adoptive parent.

Alternatively, commissioning parents in GCS are not vetted in the same way. Instead, they do the selecting (to a certain extent) in terms of choices of surrogates, donors, etc., often without any assessment as to their own suitability to parent (Fronek \& Cuthbert, 2012; SAMA, 2012). A poignant example of this can be found in the aforementioned case of Baby Gammy. This specific case raised potential issues about safeguarding the children born of GCS when previous child abuse convictions of Gammy's biological/commissioning father became known, prompting child protection investigations into his suitability to parent Gammy's (healthy) twin sister (Hawley, 2014; Jabour \& Foster, 2014). While this issue is predominately a regulatory one, it highlights as aspect of ICA (e.g. a selection process to safeguard children) that the field of surrogacy might want to consider incorporating into its practice.

\section{Hierarchy of preference}

A final point of comparison is in the importance given to having a genetic link with the child. In virtually all cases of 'stranger' adoption (i.e. the placement of children with parents who are biologically unrelated to the child), which is the norm in ICA, a genetic link between parent(s) and child is not an option, despite the notion of - and keen desire for-adopted children to be 'as if' born to the adoptive parents (Bowie, 2007; Cuthbert \& Fronek, 2014). By contrast, it is often that same desire for genetic relatedness that drives many GCS 
This is a post-acceptance, pre-publication version of the manuscript:

Scherman, R., Misca, G., Rotabi, K. \& Selman, P. (2016). Global commercial surrogacy and international adoption: A brief comparison of similarities and differences. Adoption \& Fostering. 4O(1) 30-45. doi: 10.1177/0308575915626376

arrangements (Sparrow, 2006), lending support to the notion of a hierarchy of preference. With its potential for full or part biological connection to the offspring, it appears that GCS is increasingly preferred over adoption; and surrogacies allowing for a full biological link being preferred to a partial link (van den Akker, 2007). It is this preference for a genetic link that might continue to push GCS rates upward, to the demise of ICA, which (as noted earlier) has the added advantage of also providing much-needed homes for parentless children.

\section{Surrogate mothers as compared with birth mothers in adoption}

During the Forum, the vulnerability of both surrogates in GCS and birth mothers in ICA was a dominant theme. Both groups of women were frequently seen as potentially exploited and disenfranchised, and almost always seen as coming from places of social, political and/or economic disadvantage. It was these impoverished conditions that were perceived to precipitate the need to relinquish children (in ICA) or to become surrogates (in GCS). By way of the following points of comparison, we offer the reader a better understanding of the experiences of the surrogate mother in GCS.

\section{Compensation and the socio-political climate of GCS and ICA}

Compensation for services in GCS is a fundamental point of difference when compared to ICA. The social environment of poverty and discrimination taking place (e.g.) in India is such that surrogate mothers there see GCS as well-paid employment (Pande, 2009, 2010, 2014). In fact, research carried out in Guajarat, India, reported that all of the 25 women interviewed indicated that they did not feel taken advantage of and most respondents were very direct about their need for employment (Goswami, Rotabi \& Bromfield, 2014). According to one participant:

I had some troubles. My economic condition wasn't good, and my husband didn't have a job. I couldn't even take my kids to the hospital. Then I thought, although I do have a job in the hospital I earn only Rs. 2100 [34.16 USD]. So I was thinking, with this much money, will I educate my kids or get a house for us to live or do something else? So after a lot of thinking and discussion, my husband and I took the decision that I will become a surrogate (Goswami et al., 2014, p. 5).

This quote is representative of those interviewed in this study and similar ethnographic research carried out in India: with limited opportunities and desires for housing and better education for their children, women are choosing GCS as a form of employment (Pande, 2009, 2010, 2014), with surrogacy viewed as a more desirable employment option over other forms of sometimes exploitive work (e.g. low-paid and dangerous factory work, sex work, etc.). In 
This is a post-acceptance, pre-publication version of the manuscript:

Scherman, R., Misca, G., Rotabi, K. \& Selman, P. (2016). Global commercial surrogacy and international adoption: A brief comparison of similarities and differences. Adoption \& Fostering. 4O(1) 30-45. doi: 10.1177/0308575915626376

fact, a number of reputable GCS studies, focused on the surrogates' motivations, decisionmaking, and agency (Deomampo, 2013; Karandikar, Gezinski, Carter \& Kalonga, 2014; Pande, 2009, 2014; SAMA, 2012), are showing that some surrogates feel highly empowered, running counter to media depictions of surrogates (Limon, 2013).

The experiences of these surrogates are in stark contrast to those of international birth mothers who are not compensated in the same way that surrogates receive payment. In fact, it is the hallmark of ethical ICA that no money changes hands in the process of placing children for adoption (apart from reimbursement of medical expenses and the like). In the small body of research on birth mothers in ICA, the women also expressed few choices and difficult decisions related to poverty (Rotabi, 2014). Unlike their surrogate counterparts, birth mothers do not experience a strong sense of empowerment from their decisions to relinquish. Moreover, there is no evidence indicating pregnancy or relinquishing children into adoption were considered forms of 'work'.

\section{Risk Management}

In the context of GCS, it has been reported that the fertility medical professionals in the 'good' clinics, who are dedicated to 'good' outcomes (i.e. healthy infants for the commissioning parents) as well as a positive reputation for long-term business, have developed a series of steps designed to determine a woman's suitability to become a surrogate. Among these steps is the intensive pre-screening of potential surrogates, during which time clinics may exclude women deemed not physically or emotionally appropriate for such an experience (SAMA, 2012). The women are also tested for sexually transmitted diseases and other health concerns (certain clinics even require a previous live birth as a criterion of selection), with some clinics also requiring confirmation that the woman's husband/partner is truly supportive of the commercial surrogacy arrangement (SAMA, 2012).

While it may seem that these precautions are for the benefit of the surrogate, in fact, the prescreening of potential surrogates is more accurately a form of risk management for the benefit of the commissioning parents in GCS. Subsequently, we see a failure to address the risks to the surrogate (Bishop \& Loff, 2013; Bromfield \& Rotabi, 2014), which includes health and safety issues commensurate with pregnancy, delivery, and post-delivery; the risks arising from the IVF procedures; medication side-effects; and the risks associated with multiple gestations, as the surrogates are often recruited back (SAMA, 2012). 
This is a post-acceptance, pre-publication version of the manuscript:

Scherman, R., Misca, G., Rotabi, K. \& Selman, P. (2016). Global commercial surrogacy and international adoption: A brief comparison of similarities and differences. Adoption \& Fostering. 4O(1) 30-45. doi: 10.1177/0308575915626376

Looking at adoption as a point of comparison, we do not see the same degree of risk, nor do agencies pre-screen birth mothers for health, well-being, suitability, etc. Unlike commissioning parents, for whom the surrogacy pre-screening also benefits, prospective ICA parents get no guarantees. In fact, prospective parents are often warned of the unknown elements of a child's background, as ethical agencies simply cannot promise 'healthy' children. Fundamentally, risk management does not exist in ICA as it does in GCS.

\section{Timing of the consent of relinquishment}

A final point of comparison between GCS and ICA is in the timing of the transfer of parental rights; in other words, the timing of the consent to relinquish the baby. Surrogate mothers enter into a 'contractual arrangement' prior to the pregnancy, with the agreement that she carries out gestation for another individual or couple. Therefore, by the very nature of this agreement, transfer of the child from the surrogate to the intended parent(s) takes place upon labour and delivery without a post-birth period during in which to consider her decision to surrender the baby (Fuentes, Boéchat, \& Northcott, 2012). In this context, pre-birth consent is standard practice for obvious reasons related to contracting and the expectations of the intended parent(s). In the case of adoption, such a prearranged (pre-birth) agreement would be fundamentally unethical. This is because a birth mother's rights include the importance of her choice to relinquish being made after labour and delivery, as her knowledge of the entire pregnancy experience must be part of the consent process (Rotabi, 2014).

This point of comparison speaks directly to the experience of pregnancy, the potential physiological mother-child bonding, and the emotional impact of relinquishment. In adoption, the research (across all types of adoptions) strongly indicates that the decision to relinquish is exceptionally difficult and painful, with profound and potentially long-lasting feelings of loss, grief or regret (e.g. Henney, Ayers-Lopez, McRoy \& Grotevant, 2007). It is also not uncommon for a birth mother to experience depression in response to the surrender of a child for adoption (Neil, 2007). GCS research describes some similar emotional outcomes arising from the surrender of the baby (Goswami, et al., 2014); yet the surrogates, who are recruited for the role (unlike birth mothers whose unplanned pregnancies precipitate their situations), received no pre- or post-placement counselling services (SAMA, 2012). Instead, some surrogacy clinics engage in a counselling process to reinforce the agreed upon/expected infant transfer upon birth. This, however, is not necessarily about supporting the surrogate in her decision, but rather, to help her to 'stay the course' of her initial contractual decision. Similarly, it is known that birth mother counselling in international adoptions is infrequent (Wiley \& Baden, 2005). The lack of counselling in both contexts is a commonality of poor practice, and 
This is a post-acceptance, pre-publication version of the manuscript:

Scherman, R., Misca, G., Rotabi, K. \& Selman, P. (2016). Global commercial surrogacy and international adoption: A brief comparison of similarities and differences. Adoption \& Fostering. 4O(1) 30-45. doi: 10.1177/0308575915626376

suggests weaknesses in the consent process of both contexts that may further disenfranchise birthmothers in ICA and surrogates in GCS.

\section{Children born of global surrogacy compared with adopted children}

The research literature on surrogacy prioritises the interests and experiences of the commissioning parents and the surrogate mothers, over that of the offspring. This might be due to the fact that much of the surrogacy research is still in its infancy - as are many of the children born of GCS. (For seminal research, see Pande, 2009, 2010, 2014). With some notable exceptions (Golombok, MacCallum, Murray, Lycett \& Jadva, 2006b; Golombok et al., 2011; Jadva, Blake, Casey, \& Golombok, 2012; Serafini, 2001) outcome studies are still a few years away. Alternately, it might reflect the fact that in surrogacy, the commissioning parents are the primary stakeholders and consequently, seemingly the central characters, followed second by the surrogates. Some would argue that it is the children born of surrogacy, like their counterparts in ICA, who should be the central foci (Achmad, 2014). In this final comparison, we look at a couple of ways in which the children born of GCS compare with the adopted children of ICA.

Two fundamental differences have already been established earlier in the paper: (1) the fact that surrogacy is the purposeful creation of children, whereas adoptive children already exist; and (2) that adopted children will lack a genetic link to their parents, but one which the children of surrogacy are more likely to have. Below we consider three additional points of comparison.

\section{Disclosure of origins of birth/adoptive status}

Related to the children, as well as to their parents, is the topic of disclosure. Adoptive parents and professionals have long grappled with the issue of whether, when and how to tell children that they are adopted (Carp, 2000). In the case of transracial and older child adoptions, it would be difficult to keep the adoption a secret; but for families adopting infants, decisions have to be made about when/how to disclose the adoptive status, with most research advocating for early, open and honest communication about adoption (Brodzinsky, 2005). That is because it can be devastating to find out about one's adoption later in life, wherein adopted persons "may experience significant emotional damage as they find themselves contemplating a life and what they considered to be their identity that has been based on lies and deception” (Kenny \& Higgins, 2014, p. 32). 
This is a post-acceptance, pre-publication version of the manuscript:

Scherman, R., Misca, G., Rotabi, K. \& Selman, P. (2016). Global commercial surrogacy and international adoption: A brief comparison of similarities and differences. Adoption \& Fostering. 4O(1) 30-45. doi: 10.1177/0308575915626376

When compared with families formed through donor insemination and other ART, families formed from surrogacy showed higher rates of disclosure of the surrogacy status (Readings, Blake, Casey, Jadva, \& Golombok, 2011; van den Akker, 2001). Nonetheless, like in adoption, commissioning parents in GCS also report experiencing ambiguity in when and how to disclose the relationship to the child (van den Akker, 2000). This may be an area where adoption professionals can offer assistance to GCS families in how best to disclose the surrogacy to the offspring.

\section{Identity development}

Research tells us that learning about one's adoptive status can also affect the adopted person's sense of self, otherwise known identity formation. In the field of adoption, few topics have received as much research attention as that of identity development, most of which shows a complex set of factors and outcomes in how adopted persons make sense of who they are and where they came from (Grotevant \& Von Korff, 2011). This developmental task is made even more challenging in cases of transracial adoption, common in ICA (Scherman, 2010).

Adoptive identity is not directly observable, but is characterised by an exploration of self, especially in late adolescence and early adulthood (Alvarado, Rho, \& Lambert, 2014). It is a time when, in the search for self, the individual tries on multiple identities made up of aspects of (e.g.) the adoptive family, birth/first family (either known or unknown), peer group, etc. Depending on the type of adoption (open or closed, domestic or international, etc.), the adoptee may be missing crucial identity markers to guide them (Alvarado et al., 2014). For instance, adoptees may wish to know about their genetic heritage, which clashes with birth family desires for anonymity. These added challenges make this otherwise universal task more difficult, and complicate later milestones such as the development of intimate relationships (Alvarado et al., 2014).

When we look at GCS research, the focus is still on very young children, and from the perspective of their parents (Golombok et al., 2006b; Serafini, 2001). As such, we can only conjecture on the identity development of people born of GCS. Using ICA as a comparison, many questions emerge: Will the person born of GCS see the surrogate as a type of 'birth mother', much the same as the adopted person does? Will the offspring in GCS want to travel back to the country where the surrogate lives, and will such a journey mimic the heritage trips' in international adoption? If the children born of GCS seek information about their donors, will that information be made available to them? 
This is a post-acceptance, pre-publication version of the manuscript:

Scherman, R., Misca, G., Rotabi, K. \& Selman, P. (2016). Global commercial surrogacy and international adoption: A brief comparison of similarities and differences. Adoption \& Fostering. 4O(1) 30-45. doi: 10.1177/0308575915626376

\section{Statelessness}

The final comparison between adopted persons and those born of GCS involves their citizenship. In virtually all countries, citizenship is based on either the principle of jus soli (law of the soil) or the principle of jus sanguinis (law of blood) (Goris, Harrington, \& Köhn, 2009). In the case of the former, one gains citizenship or nationality based on the country of one's birth. This birthright policy, which is rare outside of North America, exists regardless of the citizenship of one's parents (Feere, 2010). Jus sanguinis, a policy far more common throughout the world, confers citizenship on the basis of the nationality of one's parents, regardless of where one is born.

For adopted persons, depending on what country they were born into, they will almost always gain their citizenship either on the basis of their birth parents' nationality or they will become citizens of whatever countries they were born into. If adopted internationally, they will in that process change citizenship to that of the adopters, but they are rarely without citizenship. A very different situation exists for children born of GCS, who run a much greater risk of being stateless $^{5}$ in the context of citizenship. In India, for instance, only the genetic mother, who intends to raise the child, is considered the legal mother of that child. In almost all cases, because these arrangements involve gestational surrogacy, this will be the commissioning mother. In other countries like New Zealand and Norway, the legal parent is the person who gives birth to the child. In these countries, even a gestational surrogate with no biological ties to the child will be the legal parent. She would then have to surrender the child for adoption to the commissioning parents, who may be the genetic parents (Henaghan, 2014).

Statelessness occurs in the murky grey areas in between each country's laws around surrogacy and definitions of citizenship. For example, imagine that a couple from New Zealand contracts with a surrogate in India to give birth to the intended parents' genetic daughter. Once born, the child will not be recognised as an Indian national because of their laws, nor will she be considered a New Zealander because of their laws. She is stateless. Through no fault of their own, the children born of GCS sometimes find themselves without any citizenship, the consequence of which can be diabolical for the parents when they try to bring the children home, but especially so for the children who wait sometimes months or years for resolution (Kroløkke, 2012; Mahapatra, 2009; Roy, 2010). Most are eventually able to go 'home' (to the country of the commissioning parents) through diplomatic channels, the help of lawyers, judges and (sometimes) subjective interpretations of international laws (Achmad, 2014), but at what cost to the children? 
This is a post-acceptance, pre-publication version of the manuscript:

Scherman, R., Misca, G., Rotabi, K. \& Selman, P. (2016). Global commercial surrogacy and international adoption: A brief comparison of similarities and differences. Adoption \& Fostering. 4O(1) 30-45. doi: 10.1177/0308575915626376

\section{A summation of the lessons that GCS can learn from ICA}

After comparing GCS to ICA, we see a number of similarities as well as differences. Yet, there are still some key lessons that the long-standing discipline of ICA can offer the emerging field GCS.

\section{Lessons related to the commissioning parents in GCS}

Commissioning parents of GCS and ICA parents seem to have a lot in common. According to the research, both are highly committed and loving parents, with similar characteristics, including age, education and SES. Both appear to have good levels of psychological and marital functioning and demonstrate resilience in their quest for becoming parents. In terms of motivations that lead to decisions to either adopt or engage a surrogate, ICA parents are perceived to have stronger humanitarian motives for choosing adoption, given its dual outcome of also finding homes for needy children. Alternatively, commissioning parents in their preference for genetic-relatedness with their offspring are choosing surrogacy as a means of creating children. This dichotomy, best summed as the right to a child versus the rights of the child, has been the source of much debate in adoption, starting long before GCS became popular. Sadly, ICA will not likely offer GCS any lessons in how to resolve the debate. Nevertheless, one place where ICA has much to offer is in the value of having a selection process for the screening of parents. In ICA, these processes are designed to safeguard the children. Currently, no screening exists in GCS, meaning that anyone can engage a surrogate, even if for nefarious reasons ${ }^{6}$, leaving the offspring vulnerable. We believe that the field of GCS can glean much from ICA in how to best address the needs of both parents and children.

\section{Lessons related to the surrogates in GCS}

Compensation (for a service that the surrogates often see as employment) is the fundamental point of divergence between surrogates and birth mothers-who are not compensated in the same manner. On the other hand, surrogates and birth mothers share in common a characterisation in the literature as disenfranchised and vulnerable due to their circumstances of economic disadvantage. Both women are also susceptible to the negative mental health outcomes resulting from the surrender of their children. The lack of a post-birth consent process, wherein the surrogate can consider her decision to relinquish the baby, may not be so easily resolved, due to the contractual nature of GCS. Nevertheless, the years of research on birth mothers in adoption tells us that the surrender of a child can have long-lasting negative affects on one's mental well-being. This is something that the field of GCS can/should consider as it continues to hone its practices. 
This is a post-acceptance, pre-publication version of the manuscript:

Scherman, R., Misca, G., Rotabi, K. \& Selman, P. (2016). Global commercial surrogacy and international adoption: A brief comparison of similarities and differences. Adoption \& Fostering. 4O(1) 30-45. doi: 10.1177/0308575915626376

\section{Lessons related to the offspring in GCS}

ICA has long been recognised as being “... above all, a measure of child protection for children deprived of their family environment" (International Social Service, 2013, p. 2). Surrogacy, on the other hand, is the intentional creation of children for would-be parents. Despite this essential difference, there are several lessons that GCS can still learn from the field of ICA when it comes to the offspring.

First of all, as learned from adoption, disclosure will very likely be important for the children of GCS. The research from ICA tells us that it is not in the person's best interest to learn about the adoptive relationship in later life. We predict the same in GCS. Identity development may also be complicated for the offspring of GCS, especially if, like in ICA, core information related to 'self' is unavailable. When the child is old enough to ask questions about (e.g.) the donor or the surrogate, we hope that the necessary information be available.

The most important message that ICA can offer the field of GCS is that children grow up. This is a reality that was initially lost on early adoption professionals and policymakers, as many of the early practices and laws were about serving the best interests of the 'children'. It was only after the 'adopted children' grew up and began to fight for reform that any changes occurred in adoption. Laws and policies deemed to be in the best interests of safeguarding children may not be in the best interests of the adults that the children will become. For instance, the sealing of records in adoption, intended to protect all parties in the triad-but especially the children — proved to be quite damaging to adult adoptees. The field of surrogacy has the unique opportunity to do now what the field of adoption was painfully late in realising: plan for the adults that the children will eventually become. It is critical that the industry not wait for the children of global surrogacy to grow up before establishing policies and laws that support and protect them not only as children, but also as the autonomous individuals they will become.

Global commercial surrogacy, whether we like it or not, is becoming an increasingly popular method of family formation. While complex and challenging from legal, political, economic, social, and even moral perspectives, we believe that there are enough parallels with adoption to suggest that GCS should look to adoption for some important insights, that the adoption industry will no doubt be happy to share.

\section{ENDNOTES}


This is a post-acceptance, pre-publication version of the manuscript:

Scherman, R., Misca, G., Rotabi, K. \& Selman, P. (2016). Global commercial surrogacy and international adoption: A brief comparison of similarities and differences. Adoption \& Fostering. 4O(1) 30-45. doi: 10.1177/0308575915626376

1 For more information on the Forum see: http://www.iss.nl/research/conferences_and_seminars/periodic_conferences_debates_and_seminars /international_forum_on_intercountry_adoption_global_surrogacy/. For Forum reports see: http://www.iacaustralia.org/hague-forum-2015-iss-papers/

$\mathbf{2}$ Any comparison between GCS and ICA inevitably raises the question of whether we need a Convention on GCS. Across the field, a dominant concern is the uncertainty surrounding the status of many of the children born as a result of GCS. It has been ultimately concluded that it would be inappropriate the use of the 1993 Hague Convention in cases of GCS, instead recommending that the Hague Conference should carry out further study of the legal issues surrounding GCS. These conclusions have led to a series of preliminary documents (Hague Conference, 2012; 2014a) culminating in the publication in March 2014 of $A$ study of legal parentage and the issues arising from international surrogacy arrangements (Hague Conference, 2014b). All three documents are essential reading for anyone interested in the regulatory issues in GCS.

3 There are many proposed reasons for the decline in global ICA rates. For a fuller consideration, see Selman (2012).

4 A detailed discussion of the pros and cons of altruistic versus commerical surrogacy is beyond the scope of this paper. For a deeper understanding of the arguments for/against GCS, see Achmad (2014), Bromfield and Rotabi (2014), Ciccarelli, and Beckman (2005), Cutherbert and Fronek (2014), or Smolin (2004) to name just a few articles.

$\mathbf{5}$ Concerns over children's potential statelessness in GCS are paramount for all countries whose citizens are involved in the practice, especially if domestic commercial surrogacy is illegal. A full consideration of what circumstances precede statelessness is beyond the scope of this paper. For more information, see the Hague working papers at http://www.hcch.net/index_en.php?act=text.display\&tid=178

$\mathbf{6}$ In addition to concerns raised after learning that Baby Gammy's biological father had prior abuse convictions (Jabour \& Foster, 2014), it has also been reported that a Japanese man has fathered 16 children with the aid of surrogates. Many wonder what his motives are for the creation of so many babies (Rawlinson, 2014).

\section{References}

Achmad, C. (2014). International commercial surrogacy and children's rights: babies, borders, responsibilities and rights. Paper presented at the New Zealand Law Society conference, International Adoption and Surrogacy - family formation in the 21st Century, April 2014, Christchurch, Wellington and Auckland, New Zealand.

Alvarado, S. B., Rho, J. L., \& Lambert, S. F. (2014). Counseling Families With Emerging Adult Transracial and International Adoptees. The Family Journal, 22(4), 402-408. doi: $10.1177 / 1066480714548390$

Anleu, S. (1992). For love but not for money? Gender and Society, 6(1), 30-48.

Bishop, L., \& Loff, B. (2013). The rights of the gestational mother and child in surrogacy: A Bill to regulate surrogacy in India. Australian Journal of Adoption, 7(3), 1-8.

Bowie, F. (2007). Cultures of transnational adoption. Anthropological Quarterly, 80(2), 623627. 
This is a post-acceptance, pre-publication version of the manuscript:

Scherman, R., Misca, G., Rotabi, K. \& Selman, P. (2016). Global commercial surrogacy and international adoption: A brief comparison of similarities and differences. Adoption \& Fostering. 4O(1) 30-45. doi: 10.1177/0308575915626376

Brodzinsky, D. M. (2005). Reconceptualizing openness in adoption: Implications for theory, research, and practice. In D. Brodzinsky \& J. Palacios (Eds.), Psychological Issues in Adoption: Research and Practice (pp. 145-166). New York: Praeger Publishers.

Bromfield, N. F., \& Rotabi, K. S. (2014). Global Surrogacy, Exploitation, Human Rights and International Private Law: A Pragmatic Stance and Policy Recommendations. Global Social Welfare, 1(3), 123-135. doi: 10.1007/s40609-014-0019-4

Carp, E. W. (2000). Family matters: Secrecy and disclosure in the history of adoption. Cambridge, MA: Harvard University Press.

Ciccarelli, J. C., \& Beckman, L. J. (2005). Navigating rough waters: An overview of psychological aspects of surrogacy. Journal of Social Issues, 61(1), 2 1-43. doi: $10.1111 /$ j.0022-4537.2005.00392.x

Crawshaw, M., Blyth, E. \& van den Akker, O. (2013). The changing profile of surrogacy in the UK - Implications for national and international policy and practice. Journal of Social Welfare and Family Law, 34(3), 1-1 1. doi: 10.1080/09649069.2012.750478

Crea, T. M. (2012). Intercountry adoptions and home study assessments: The need for uniform practices. . In J. Gibbons \& K.S. Rotabi (Eds.), Intercountry Adoption: Policies, Practices, and Outcomes (pp. 265-272). Surrey, England: Ashgate Press.

Cuthbert, D., \& Fronek, P. (2014). Perfecting adoption? Reflections on the rise of commercial offshore surrogacy and family formation in Australia. In, Families, policy and the Law. Australian Institute of Family Studies: Australian Government.

Darnovsky, M. \& Beeson, D. (2014). Global Surrogacy Practices, Report from the International Forum on Intercountry Adoption and Global Surrogacy, The Hague, 11-13 August 2014, The Hague: Institute of Social Studies Working Paper no 601. Retrieved from http://repub.eur.nl/pub/77402/wp601.pdf

Deomampo, D. (2013). Transnational surrogacy in India: Interrogating power and women's agency. Frontiers: Journal of Women's Studies, 34(3), 167-188.

DasGupta S. \& DasGupta S. D. (2010). Motherhood jeopardized: Reproductive technologies in Indian communities. In W. Chavkin \& J.M. Maher (Eds.), The Globalization of Motherhood. London: Routledge.

Feere, J. D. (2010). Birthright Citizenship in the United States: A Global Comparison. Center for Immigration Studies. Retrieved from http://cis.org/birthright-citizenship

Fisher, A. P. (2003). Still "not quite as good as having your own"? Toward a sociology of adoption. Annual Review of Sociology, 335-361. doi:10.1146/annurev.soc.29.010202.100 
This is a post-acceptance, pre-publication version of the manuscript:

Scherman, R., Misca, G., Rotabi, K. \& Selman, P. (2016). Global commercial surrogacy and international adoption: A brief comparison of similarities and differences. Adoption \& Fostering. 4O(1) 30-45. doi: 10.1177/0308575915626376

Fronek, P. \& Cuthbert, D. (2012). The future of inter-country adoption: A paradigm shift for this century. International Journal of Social Welfare, 21(2), 215-224. doi: 10.1111/j.1468-2397.2011.00799.x

Fuentes, F., Boéchat, H., \& Northcott, F. (2012). Investigating the Grey Zones in Intercountry Adoption. Geneva, Switzerland: International Social Service. ISBN 978-2-8399-1000-2

Golombok, S., Murray, C., Jadva, V., MacCallum, F., \& Lycett, E. (2004). Families created through surrogacy arrangements: parent-child relationships in the 1st year of life. Developmental Psychology, 4O(3), 400-411. doi: 0.1037/0012-1649.40.3.400

Golombok, S., Murray, C., Jadva, V., Lycett, E., MacCallum, F., \& Rust, J. (2006a). Nongenetic and non-gestational parenthood: consequences for parent-child relationships and the psychological well-being of mothers, fathers and children at age 3. Human Reproduction, 21(7), 1918-1924. doi: 10.1093/humrep/delo39

Golombok S., MacCallum F., Murray C., Lycett E., \& Jadva V. (2006b). Surrogacy families: parental functioning, parent-child relationships and children's psychological development at age 2. Journal of Child Psychology and Psychiatry, 47, 213-222. doi: $10.1111 /$ j.1469-7610.2005.01453.x

Golombok, S., Readings, J., Blake, L., Casey, P., Marks, A., \& Jadva, V. (2011). Families created through surrogacy: Mother-child relationships and children's psychological adjustment at age 7. Developmental psychology, 47(6), 1579-1588. doi: $10.1037 / \mathrm{a} 0025292$

Goris, I., Harrington, J., \& Köhn, S. (2009). Statelessness: what it is and why it matters. Forced Migration Revier, 32(6), 4-6.

Goswami, L., Rotabi, K. S. \& Bromfield, N. F. (2014, August). Force, fraud, coercion and exploitation: Abuses in intercountry adoption contrasted against what Indian women acting as surrogate mothers have to say about their experiences, Paper presented at the Forum on Intercountry Adoption and Global Surrogacy. The Hague, Netherlands.

Grotevant, H. D., \& Von Korff, L. (2011). Adoptive identity. In S. Schwartz, K. Luyckx, \& V. Vignoles (Eds.) Handbook of identity theory and research (pp. 585-601). Springer: New York.

Hague Conference on Private International Law (2012). A preliminary report on the issues arising from international surrogacy arrangements. The Hague: Permanent Bureau.

Hague Conference on Private International Law (2014a) The Desirability and Feasibility of Further Work on the Parentage/Surrogacy Project, Preliminary document 3b of March 
This is a post-acceptance, pre-publication version of the manuscript:

Scherman, R., Misca, G., Rotabi, K. \& Selman, P. (2016). Global commercial surrogacy and international adoption: A brief comparison of similarities and differences. Adoption \& Fostering. 4O(1) 30-45. doi: 10.1177/0308575915626376

2014 for the Council of April 2014 on General Affairs and Policy of the Conference. The Hague: $\mathrm{HCCH}$. Retrieved from

http://www.hcch.net/upload/wop/gap2014pdo3b_en.pdf

Hague Conference (2014b). A study of legal parentage and the issues arising from international surrogacy arrangements. Preliminary Document No 3 C of March 2014 for the Council of April 2014 on General Affairs and Policy of the Conference. The Hague: HCIA. Retrieved from: http://www.hcch.net/upload/wop/gap2014pdo3c_en.pdf

Hawley, S. (2 September, 2014). Australian charged with sexually abusing twins he fathered with Thai surrogate. $A B C$ Neres. Retrieved from: http://www.abc.net.au/news/201409-01/australian-who-fathered-surrogate-twins-facing-abuse-charges/5710796

Henaghan, M. (2014). Future models for international surrogacy: Proposals for change. Paper presented at the New Zealand Law Society conference, International Adoption and Surrogacy - family formation in the 21st Century, April 2014, Christchurch, Wellington and Auckland, New Zealand.

Henney, S. M., Ayers-Lopez, S., McRoy, R. G., \& Grotevant, H. D. (2007). Evolution and resolution: Birthmothers' experience of grief and loss at different levels of adoption openness. Journal of Social and Personal Relationships, 24(6), 875-889.

Hornery, A. (18 January, 2011). Nicole Kidman and Keith Urban have daughter through surrogate mother. The Sunday Morning Herald. Retrieved from: http://www.smh.com.au/lifestyle/celebrity/nicole-kidman-and-keith-urban-havedaughter-through-surrogate-mother-20110117-19ueu.html

India News (2014). India to have new surrogacy law soon, New Delhi: India News, 16 November 2014. Retrieved from http://www.deccanherald.com/content/441937/india-have-surrogacy-lawsoon.html

International Social Service (2014). The adoption of older children: A project that measures up to the children's needs? (First part) ISS Monthly Review, 181, May. 
This is a post-acceptance, pre-publication version of the manuscript:

Scherman, R., Misca, G., Rotabi, K. \& Selman, P. (2016). Global commercial surrogacy and international adoption: A brief comparison of similarities and differences. Adoption \& Fostering. 4O(1) 30-45. doi: 10.1177/0308575915626376

Jabour, B \& Foster, B. (5 August, 2014) Child abuse convictions of Gammy's father prompt investigation: Australian child protection workers to check on wellbeing of Gammy's sister, as surrogate mother says she wants girl back. The Guardian. Retrieved from: http://www.theguardian.com/world/2014/aug/05/gammy-father-child-abuseconvictions-investigation

Jadva, V., Blake, L., Casey, P., \& Golombok, S. (2012). Surrogacy families 10 years on: relationship with the surrogate, decisions over disclosure and children's understanding of their surrogacy origins. Human Reproduction, advance access, doi:10.1093/humrep/des273

Joyce, K. (2013) The Child Catchers: Rescue, Trafficking, and the Nerw Gospel of Adoption. New York: Public Affairs.

Karandikar, S., Gezinski, L. B., Carter, J. R. \& Kalonga, M. (online first, January 2014). Economic necessity or noble cause? A qualitative study exploring motivations for gestational surrogacy in Gujarat, India, Affilia, doi: 10.1177/0886109913516455

Kenny, P. \& Higgins, D. (2014). Past adoption practices: Key messages for service delivery responses and current policies. In A. Hayes \& D. Higgins (Eds.). Families, policy and the law: Selected essays on contemporary issues for Australia. Australian Institute of Family Studies.

Kroløkke, C. (2012). From India with love: Troublesome citizens of fertility travel. Cultural Politics, 8(2), 307-325. doi: 10.1215/17432197-1575183

Limon, C. (2013). Surrogacy and parenthood: An overview of the research on the relationship between surrogacy and adoption. Australian Journal of Adoption, 7(3), 116.

Mahapatra, D. (16 December, 2009). German couple's surrogate kids may end up stateless. The Times of India. Retrieved from: http:/ / timesofindia.indiatimes.com/india/German-couples-surrogate-kids-may-endup-stateless/articleshow/5340835.cms

McCoy, T. (4 August, 2014). How a Thai baby with Down Syndrome raised questions about global surrogacy. The Washington Post. Retrieved from: http://www.washingtonpost.com/news/morning-mix/wp/2014/08/04/the-thaibaby-with-down-syndrome-and-a-controversy-about-global-surrogacy/

Misca, G. (2013) The 'Quiet Migration', in Contemporary Issues in Family Studies: Global Perspectives on Partnerships, Parenting and Support in a Changing World (eds A. Abela and J. Walker), John Wiley \& Sons, Oxford. doi: 10.1002/9781118320990.ch20 
This is a post-acceptance, pre-publication version of the manuscript:

Scherman, R., Misca, G., Rotabi, K. \& Selman, P. (2016). Global commercial surrogacy and international adoption: A brief comparison of similarities and differences. Adoption \& Fostering. 4O(1) 30-45. doi: 10.1177/0308575915626376

Misca, G. (2014). The “Quiet Migration”: Is Intercountry Adoption a Successful Intervention In the Lives of Vulnerable Children?. Family Court Reviere, 52(1), 60-68. doi: $10.1111 /$ fcre. 12070

Neil, E. (2007). Coming to terms with the loss of a child: The feelings of birth parents and grandparents about adoption and post-adoption contact. Adoption quarterly, 1O(1), 123.

Pande, A. (2009). 'Not an angel' not 'a whore': Surrogates as 'dirty workers' in India. Indian Journal of Gender Studies, 16, 141-173. doi: 10.1177/097152150901600201

Pande, A. (2010). Surrogacy in India: Manufacturing a perfect mother-worker. Signs, 35(4), 968-992.

Pande, A. (2014). Wombs in labor: Transnational Commercial Surrogacy in India, New York: Columbia University Press.

Rawlinson, K. (23 August, 2014). Interpol investigates 'baby factory' as man fathers 16 surrogate children. The Guardian, 23 August 2014. Retrieved from: http://www.theguardian.com/lifeandstyle/2014/aug/23/interpol-japanesebaby-factory-man-fathered-16-children

Readings, J., Blake, L., Casey, P., Jadva, V., \& Golombok, S. (2011). Secrecy, disclosure and everything in-between: decisions of parents of children conceived by donor insemination, egg donation and surrogacy. Reproductive Biomedicine Online, 22(5), 485495. doi: 10.1016/j.rbmo.2011.01.014

Rogers, D. \& Watcharasakwet, W. (3 August, 2014). Thai baby's plight raises questions on global surrogacy rules. The Wall Street Journal. Retrieved from: http://online.wsj.com/articles/abandonment-of-thai-baby-raises-questions-onglobal-surrogacy-rules-1407075668

Rotabi, K. S. (December, 2014). Force, fraud, and coercion: Bridging from knowledge in intercountry adoption to global surrogacy. Report for Thematic Area 4 of the International Forum on Intercountry Adoption and Global Surrogacy held in August 2014. International Institute of Social Sciences, The Hague, NL. Retrieved from http://repub.eur.nl/pub/77403/wp600.pdf

Rotabi, K. S., Bromfield, N. F. \& Fronek, P. (2015). International private law to regulate commercial global surrogacy practices: Just what are social work's practical policy recommendations? International Social Work.

Rotabi, K. S., \& Bromfield, N. F. (2012). Intercountry adoption declines lead to new practices of global surrogacy in Guatemala: Global human rights concerns in the context of 
This is a post-acceptance, pre-publication version of the manuscript:

Scherman, R., Misca, G., Rotabi, K. \& Selman, P. (2016). Global commercial surrogacy and international adoption: A brief comparison of similarities and differences. Adoption \& Fostering. 4O(1) 30-45. doi: 10.1177/0308575915626376

violence and the era of advanced fertility technology. Affilia, 27(2), 129-141. doi: $10.1177 / 0886109912444102$

Roy, S. D. (9 June, 2010). French gay dad may lose surrogate kids. The Times of India.

Retrieved from: http://timesofindia.indiatimes.com/india/French-gay-dad-may-losesurrogate-kids/articleshow/6025936.cms

SAMA-Resource Group for Women and Health (2012). Birthing a Market: A Study on Commercial Surrogacy. Retrieved from: http://www.samawomenshealth.org/downloads/Birthing\%20A\%20Market.pdf

San Roman, B. \& Marre, D. (forthcoming). Understanding the fluxes of adoption demand: the Spanish case.

Scherman, R. (2010). A theoretical look at biculturalism in intercountry adoption. Journal of ethnic and cultural diversity in social work, 19(2), 127-142. doi: 10.1080/15313201003771742

Selman, P. (2012). The global decline of intercountry adoption: What lies ahead?. Social Policy and Society, 11 (03), 381-397.

Selman, P. (2015). Key Tables for Intercountry Adoption Receiving States and States of Origin 2003-2013. Retrieved from: http://www.hcch.net/index_en.php?act=publications.details\&pid=5891\&dtid=32

Serafini, P. (2001). Outcome and follow-up of children born after IVF-surrogacy. Human Reproduction Update, 7(1), 23-27. doi: 10.1093/humupd/7.1.23

Sifris, A. (2014). Gay and Lesbian parenting: The legislative response. In Families, policy and the law. Australian Institute of Family Studies: Australian Government.

Smolin, D. M. (2004). Intercountry adoption as child trafficking. Valparaiso University Law Review, 39, 281-325.

Sparrow, R. (2006). Cloning, parenthood, and genetic relatedness. Bioethics, 20(6), 308-318. doi: $10.1111 /$ j.1467-8519.2006.00509.x

Topping, A, \& Foster, B. (4 August, 2014). International surrogacy laws in the spotlight amid row over baby Gammy. The Guardian. Retrieved from: http://www.theguardian.com/world/2014/aug/04/global-surrogacy-laws-debatebaby-gammy-thailand

Twine, F. W. (2011). Outsourcing the Womb: Race, Class and Gestational Surrogacy in a Global Market. New York: Routledge. 
This is a post-acceptance, pre-publication version of the manuscript:

Scherman, R., Misca, G., Rotabi, K. \& Selman, P. (2016). Global commercial surrogacy and international adoption: A brief comparison of similarities and differences. Adoption \& Fostering. 4O(1) 30-45. doi: 10.1177/0308575915626376

van den Akker, O. (2000). The importance of a genetic link in mothers commissioning a surrogate baby in the UK. Human reproduction, 15(8), 1849-1855. doi: 10.1093/humrep/15.8.1849

van den Akker, O. (2001). Adoption in the age of reproductive technology. Journal of Reproductive and Infant Psychology, 19(2), 147-159. doi: 10.1080/02646830125231

van den Akker, O. B. (2007). Psychosocial aspects of surrogate motherhood. Human Reproduction Update, 13(1), 53-62. doi: 10.1093/humupd/dmlo39

Wang, P. Y. (2015) Thailand bans commercial surrogacy for foreigners, singles. Bangkok: The Associated Press, 7 August 2015. Retrieved from http://www.businessinsider.com/ap-thailand-bans-commercial-surrogacy-forforeigners-singles-2015-8? IR $=\mathrm{T}$

Widdows, H., \& MacCallum, F. (2002). Disparities in parenting criteria: An exploration of the issues, focusing on adoption and embryo donation. Journal of Medical Ethics, 28, 139-142.

Wiley, M. O. L., \& Baden, A. L. (2005). Birth Parents in Adoption Research, Practice, and Counseling Psychology. The Counseling Psychologist, 33(1), 13-50. doi: 10.1177/0011000004265961

Zhang, Y., \& Lee, G. R. (2011). Intercountry Versus Transracial Adoption: Analysis of Adoptive Parents' Motivations and Preferences in Adoption. Journal of Family Issues, 32(1), 75-98. doi: 10.1177/0192513x10375410 
This is a post-acceptance, pre-publication version of the manuscript:

Scherman, R., Misca, G., Rotabi, K. \& Selman, P. (2016). Global commercial surrogacy and international adoption: A brief comparison of similarities and differences. Adoption \& Fostering. 4O(1) 30-45. doi: 10.1177/0308575915626376

\footnotetext{
${ }^{1}$ For more information on the Forum see: http://www.iss.nl/research/conferences_and_seminars/periodic_conferences_debates_and_seminars /international_forum_on_intercountry_adoption_global_surrogacy/. For Forum reports see: http://www.iacaustralia.org/hague-forum-2015-iss-papers/
}

${ }^{2}$ Any comparison between GCS and ICA inevitably raises the question of whether we need a Convention on GCS. Across the field, a dominant concern is the uncertainty surrounding the status of many of the children born as a result of GCS. It has been ultimately concluded that it would be inappropriate the use of the 1993 Hague Convention in cases of GCS, instead recommending that the Hague Conference should carry out further study of the legal issues surrounding GCS. These conclusions have led to a series of preliminary documents (Hague Conference, 2012; 2014a) culminating in the publication in March 2014 of A study of legal parentage and the issues arising from international surrogacy arrangements (Hague Conference, 2014b). All three documents are essential reading for anyone interested in the regulatory issues in GCS.

3 There are many proposed reasons for the decline in global ICA rates. For a fuller consideration, see Selman (2012).

4. A detailed discussion of the pros and cons of altruistic versus commerical surrogacy is beyond the scope of this paper. For a deeper understanding of the arguments for/against GCS, see Achmad (2014), Bromfield and Rotabi (2014), Ciccarelli, and Beckman (2005), Cutherbert and Fronek (2014), or Smolin (2004) to name just a few articles.

${ }^{5}$ Concerns over children's potential statelessness in GCS are paramount for all countries whose citizens are involved in the practice, especially if domestic commercial surrogacy is illegal. A full consideration of what circumstances precede statelessness is beyond the scope of this paper. For more information, see the Hague working papers at http://www.hcch.net/index_en.php?act=text.display\&tid=178

6 In addition to concerns raised after learning that Baby Gammy's biological father had prior abuse convictions (Jabour \& Foster, 2014), it has also been reported that a Japanese man has fathered 16 children with the aid of surrogates. Many wonder what his motives are for the creation of so many babies (Rawlinson, 2014). 